\title{
ESTUDO HIDROGEOLÓGICO DOS SEDIMENTOS LITORÂNEOS DO SUL DO ESTADO DA BAHIA
}

\author{
JOAQUINA LACERDA LEITE*
}

\begin{abstract}
The eighteen wells drilled by the Companhia de Engenharia Rural da Bahia, and the data of pumping tests, permited us to estimate some hydrogeologics properties of the tertiary and quaternary sediments of the South Coast of the State of Bahia. The application of the resistivity method of geophysical prospecting allowed us to make a more detailed study of these aquifers. It was determinated by the well discharge, the porosity, the permeability, the clay content, the specific yield, the quality of groundwater and the vertical and lateral extension of the aquifers around Canavieiras and Belmonte.
\end{abstract}

INTRODUÇÃO A pluviometria da faixa costeira do Sul do Estado da Bahia é bastante alta, em geral superior a $1.500 \mathrm{~mm} / \mathrm{a}$, sendo também abundante a sua rede fluvial. Entretanto, a baixa altitude da área, permitindo a invasão constante de seus rios pela água salgada do mar, proíbe o aproveitamento dos seus mananciais de água para fins de abastecimento coletivo. Felizmente, quase todos os centros urbanos da costa coincidem com a desembocadura de um rio permanente, tendo muitos deles propiciado o desenvolvimento de extensas áreas aluvionares que, algumas vezes, avançam para o continente mais de 30 quilômetros. Assim, grande parte da faixa litorânea encontra-se recoberta por sedimentos quaternários pertencentes à Bacia Sedimentar Bahia Sul/Espirito Santo, os quais vêm fornecendo a água necessária às localidades da área.

Até há bem poucos anos atrás, a captação de água subterrânea, no litoral sul da Bahia, era feita mediante o obsoleto sistema de bombeamento individual de poços cavados no fundo dos quintais que, além de ser contraproducente, em geral não satisfaz aos requisitos recomendados pelas normas de saúde pública. Ultimamente, a Companhia de Engenharia Rural da Bahia (CERB) vem perfurando alguns poços na faixa litorânea, os quais permitem fazer-se uma avaliação preliminar das características hidrogeológicas dos seus sedimentos quaternários de recobrimento.

A aceleração do progresso das cidades costeiras do. sul do Estado da Bahia, como conseqüência da construção da rodovia federal BR-101, vem demandando uma quantidade cada vez maior de água, não só para o consumo da população mas também para o suprimento das pequenas indústrias que vêm surgindo. Desse modo, dada a importância da água subterrânea para aquelas localidades, torna-se imprescindivel um estudo de caracterização da província hidrogeológica do litoral sul do Esta do da Bahia.

O presente trabalho consta de um estudo regional dessa província, utilizando-se como referência os dados dos poços perfurados pela CERB na faixa costeira compreendida entre Belmonte e Nova Viçosa (Fig. 1). Consta ainda de um estudo geofísico detalhado das reservas de água subterrânea dos aluviões quaternários das áreas vizinhas a Belmonte e a Canavieiras, através do método de eletrorresistividade.

CARACTERIZAÇÃO DA ÁREA A área estudada compreende uma faixa litorânea de aproximadamente 10 quilômetros de largura, limitada pelas latitudes $15^{\circ} 30^{\prime} \mathrm{S}$ e $18^{\circ} \mathrm{S}$. De acordo com a classificaçâo de Köppen, o clima da área é do tipo Af, quente e úmido, sem estação seca, com periodo chuvoso de março a agosto, e com chuvas esparsas nos demais meses. $O$ valor médio da pluviometria, para os últimos anos, oscila entre 1.500 e $1.750 \mathrm{~mm} / \mathrm{a}$ (Diagnóstico Sócio-Econômico do Estado da Bahia, 1975) enquanto a evapotranspiração média real, calculada para os diversos períodos, é de $1.150 \mathrm{~mm} / \mathrm{a}$ (Minist. Agricultura, 1972).

A rede hidrográfica da área é bastante extensa, po. dendo-se citar como mais importantes os rios Itanhém (que deságua em Alcobaça), Paripe (em Nova Viçosa), Jacuruçu (em Prado), Jequitinhonha (em Belmonte), Pardo (em Canavieiras), Buranhém (em Porto Seguro) e João de Tiba (em Santa Cruz de Cabrália).

Do ponto de vista geomorfológico, a faixa litorânea apresenta-se como uma planície flúvio-marinha e aluvial, caracterizada pela presença de extensos cordões litorâneos paralelos ou oblíquos à linha de praia, os quais chegam a alcançar extensões de 13 quilômetros para o interior (na área de Caravelas, Alcobaça e Nova Viçosa) ou de até 20 quilômetros em Belmonte e Canavieiras. Ao longo dos rios principais ocorrem aluviōes recentes, com larguras variando normalmente de 1 a 4 quilômetros, sendo mais desenvolvidos no curso do Rio Jequitinhonha, onde atingem larguras de 8 quilômetros.

É interessante observar, no mapa geológico da Fig. 1, que a planície flúvio-aluvial marinha é inexpressiva no litoral compreendido pelas latitudes $16^{\circ} \mathrm{S}$ e $17^{\circ} 15^{\prime} \mathrm{S}$. Nessa faixa, bem com a oeste de toda a planície aluvial, encontramos os tabuleiros, de relevo bastante acidentado e com cotas variando em torno de 100 metros. Esses tabuleiros são constituidos de sedimentos terciários da formação Barreiras. 


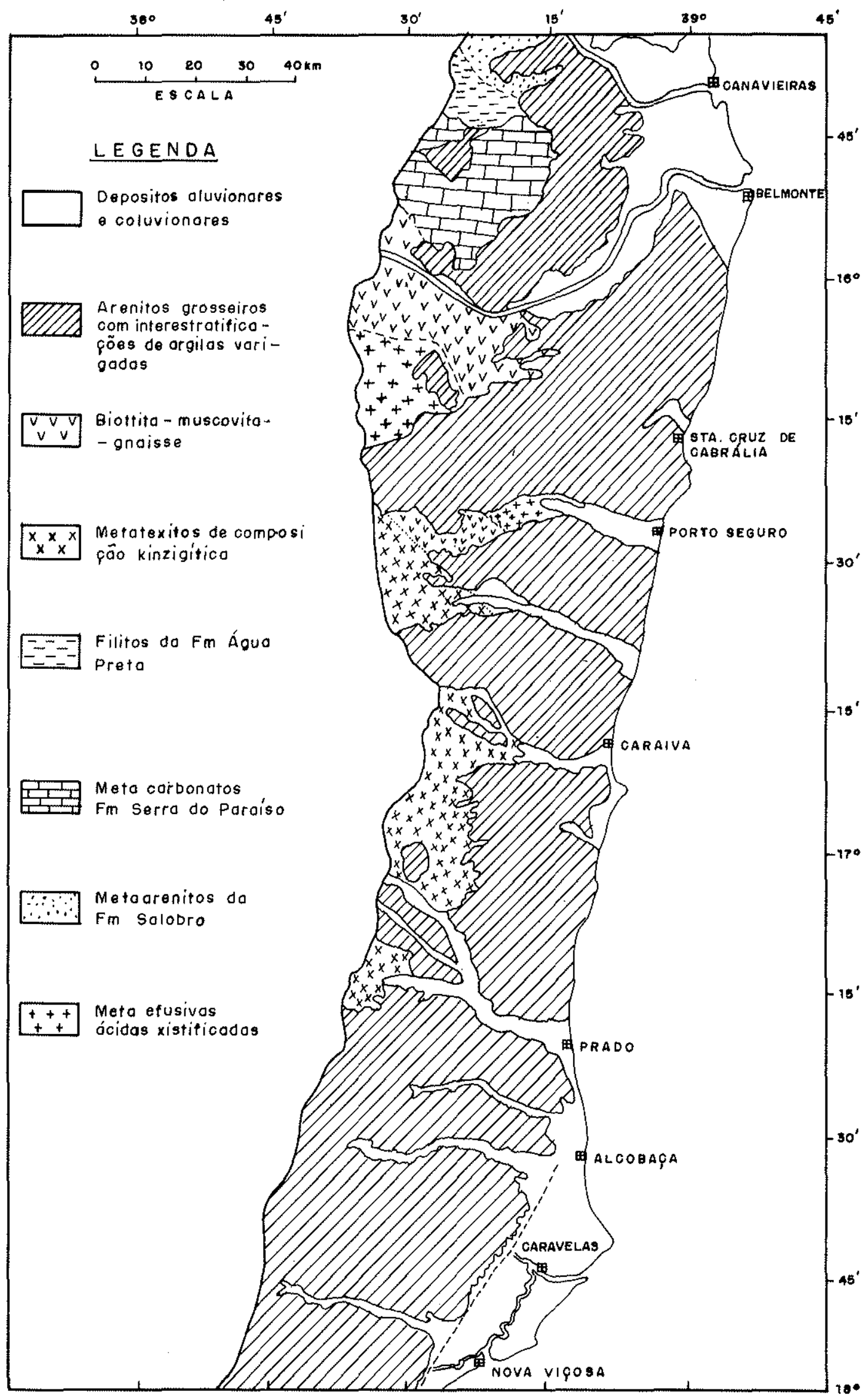

Figura 1 - Mapa geológico do litoral sul da Bahia (Fonte: DNPM/CRPM, 1974) 
A estratigrafia da faixa costeira apresenta-se variável, podendo-se distinguir três zonas distintas:

Zona I - compreendendo os municípios de Belmonte e Canavieiras;

Zona II - compreendendo os municípios de Santa Cruz de Cabrália e Porto Seguro;

Zona III - compreendendo os municípios de Prado, Alcobaça, Caravelas e Nova Viçosa.

A geologia local da zona I foi estudada em detalhe por Pedreira (1971). Seus estudos revelaram ser o substrato da área constituído por metassedimentos precambrianos superpostos por sedimentos terciários e quaternários.

O período terciário é representado pela formação Barreiras, constituída de arenitos inconsolidados, seixos, conglomerados e areias, todos intercalados por níveis argilosos, conforme constatado pelos poços SAl BA e CPN1 - BA, perfurados pela PETROBRÁS (Relatório interno).

Os sedimentos inconsolidados de idade quaternária recobrem a formação Barreiras, ao longo de toda a costa, numa faixa cuja largura chega a ultrapassar 20 quilômetros. Em geral, esses aluviões são areias grosseiras, quartzosas e micáceas, puras ou argilosas, intercaladas com argilas, as quais atingem, algumas vezes, $100 \mathrm{me}-$ tros de espessura, conforme pode ser observado nos perfis litológicos dos poços perfurados em Belmonte (Fig. 2).

A zona II diferencia-se da zona I por se apresentar quase totalmente recoberta por sedimentos terciários, superpostos discordantemente sobre o embasamento precambriano. Os poços perfurados pela CERB, em Santa Cruz de Cabrália, atingiram a profundidade de $53 \mathrm{~m}$, sem encontrar o embasamento cristalino. Num corte existente na estrada Eunápolis-Porto Seguro, os sedimentos terciários apresentam uma espessura de 70 metros. Esses dados, aliado ao fato das rochas precambrianas estarem expostas nos vales dos rios que cortam os tabuleiros, parecem indicar ser improvável uma espessura superior a 100 metros, para os sedimentos da formação Barreiras.

Os estudos estratigráficos realizados na zona 11 , por técnicos da CPRM (Projeto Bahia Sul, 1974), concluiram pela existência de 3 tipos litológicos distintos: rochas quaternárias pertencentes à formação Caravelas, assentadas sobre as rochas da formação Barreiras, as quais encontram-se sobrejacentes ao embasamento cristalino.

A formação Caravelas, com espessura estimada em 2.800 metros (Asmus, 1971), é constituída de sedimentos carbonáticos intercalados por areia, argila e folhelho. Sobre esses sedimentos, encontramos uma delgada camada de depósitos recentes, constituídos de material arenoso, na costa, e argilo-arenoso, ao longo dos principais rios.

A constituição litológica da formação Barreiras é bastante diversificada, porém, de um modo geral, apresenta as mesmas características em todas as três zonas. Sua espessura varia desde poucos metros até 250 metros, de acordo com dados de poços estratigráficos perfurados pela Petrobrás, em vários locais da Bacia Sedi- mentar Bahia Sul/Espírito Santo (Carvalho e Garrido, 1966).

CARACTERÍSTICAS HIDROGEOLÓGICAS DA ÁREA No seu trabalho "Geologia e Províncias Hidrogeológicas da Bahia", Brito Neves e Manoel Filho (1972) propõem 7 províncias hidrogeológicas para o Estado. A área do presente estudo está incluída em duas diferentes províncias, denominadas Depósitos Cenozóicos e Bacias Mezozóicas Oriéntais, conforme pode ser apreciado na Fig. 3. Entretanto, devido à falta de dados de perfuração, naquela época eles não apresentaram informações quantitativas a respeito das propriedades hidrogeológicas dos aquíferos da faixa litorânea do sul da Bahia. Posteriormente, em 1975, a CERB lançou o seu catálogo de poços, incluindo uma relação de 9 poços na zona I, 2 poços na zona II e 7 poços na zona III (Fig. 2). Os dados desses poços serviram de subsídio para grande parte deste trabalho.

Os perfis litológicos dos poços perfurados pela CERB, e desenhados na Fig. 2, bem como os seus elementos hidrogeológicos (Tab. 1), permitiram as observações feitas a seguir. $\dot{E}$ importante salientar que os dados de bombeamento disponíveis só possibilitaram determinar duas propriedades hidrodinâmicas, a vazão específica e a transmissividade. Esta foi calculada pelas fórmulas de Theis, para os dados de rebaixamento, e de Jacob para a recuperação (Todd, 1959). A permeabilidade não pode ser determinada devido à falta de poços de observação nos ensaios de bombeamento.

Infelizmente, a maioria dos poços de Canavieiras é bastante rasa, com profundidade entre 20 e 30 metros. Em vista disso, só permite visualizar uma única camada aquífera, não confinada, bastante rasa, e com espessura média de 18 metros. As vazões medidas nesses poços variam entre $2,2 \mathrm{~m}^{3} / \mathrm{h}$, e $36 \mathrm{~m}^{3} / \mathrm{h}$, para rebaixamentos entre 0,61 metros e 12,20 metros. Esses valores đão vazões específicas dentro do intervalo $0,28 \mathrm{~m}^{3} / \mathrm{h} / \mathrm{m}-59 \mathrm{~m}^{3} /$ $/ \mathrm{h} / \mathrm{m}$. O coeficiente de transmissividade desse nível arenoso é bastante alto, variando de $4,4 \times 10^{-2} \mathrm{~m}^{2} / \mathrm{min}$ a $2,1 \mathrm{~m}^{2} / \mathrm{min}$. A granulometria da areia é muito variável, encontrando-se tanto areias grossas quanto areias finas e médias, no mesmo poço. Essa diversidade granulométrica, aliada ao fato da areia nem sempre encontrar-se pura, são alguns dos fatores que concorrem para o amplo intervalo de variação da vazão específica. É interessante salientar que o poço $P 1$ revela a existência de aquíferos mais profundos, constituidos de arenitos e conglomerados, confinados por material argiloso. Neste poço foi detetada a presença de água salgada, a qual não se relaciona com a intrusão da água do mar, conforme ficou demonstrado por Leite (1975).

Um dos poços de Belmonte revela apenas um espesso nível arenoso, com mais de 50 metros de espessura. $\mathrm{O}$ outro poço atravessa 2 niveis arenosos, ambos confinados. As vazões de produção desses poços são $52,8 \mathrm{~m}^{3} / \mathrm{h}$ e $39,6 \mathrm{~m}^{3} / \mathrm{h}$, respectivamente. Entretanto quando bombeados, eles experimentam elevados valores de rebaixamento, de tal modo que suas vazões específicas são baixas, $3,82 \mathrm{~m}^{3} / \mathrm{h} / \mathrm{m}$ e $1,31 \mathrm{~m}^{3} / \mathrm{h} / \mathrm{m}$. A ordem de grandeza da transmissividade de ambos os níveis arenosos é de $10^{-2} \mathrm{~m}^{2} / \mathrm{min}$. 


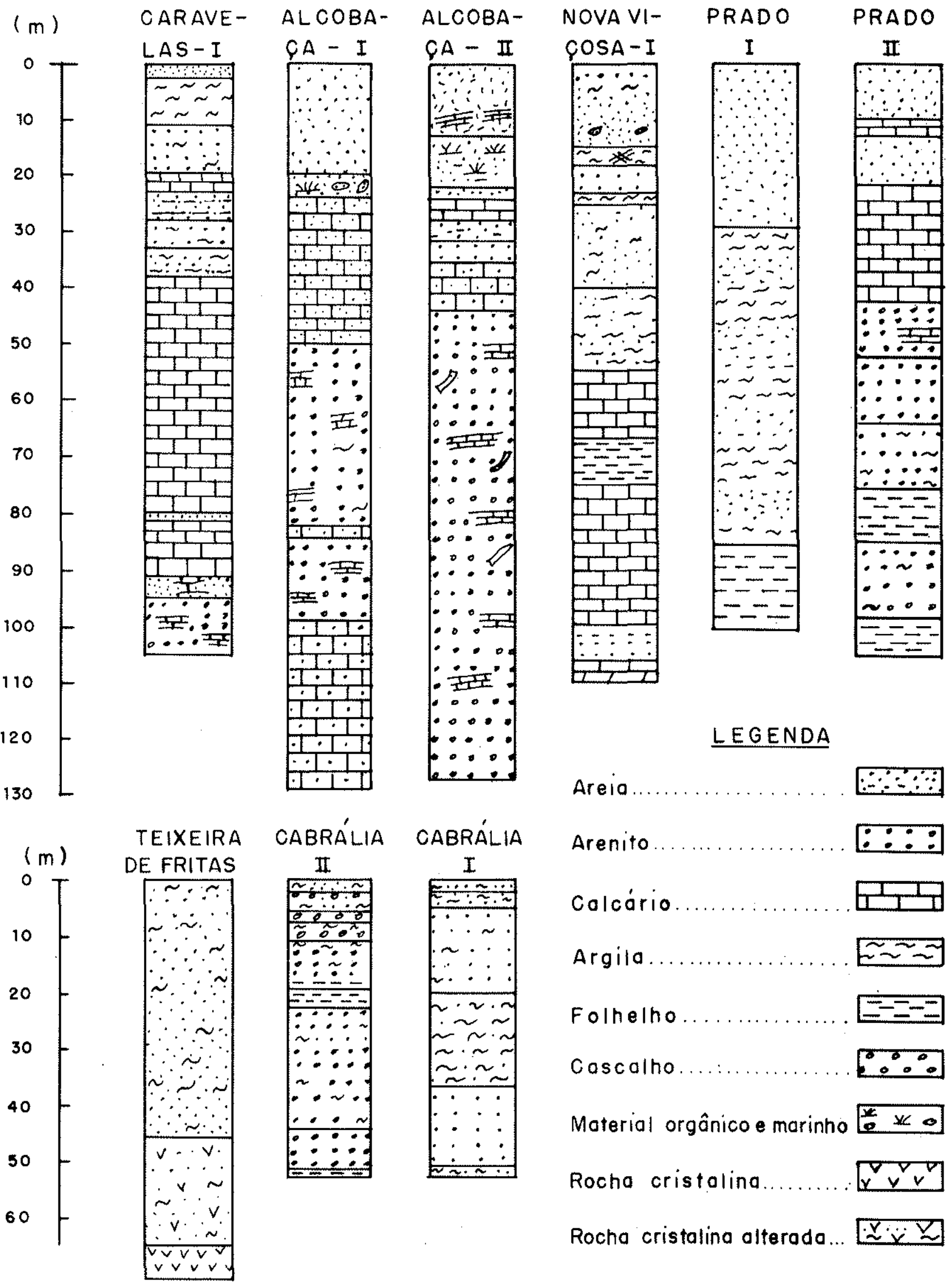

Figura 2.1 - Perfís litológicos dos poços tubulares do litoral sul da Bahia (Fonte: CERB, 1975) 


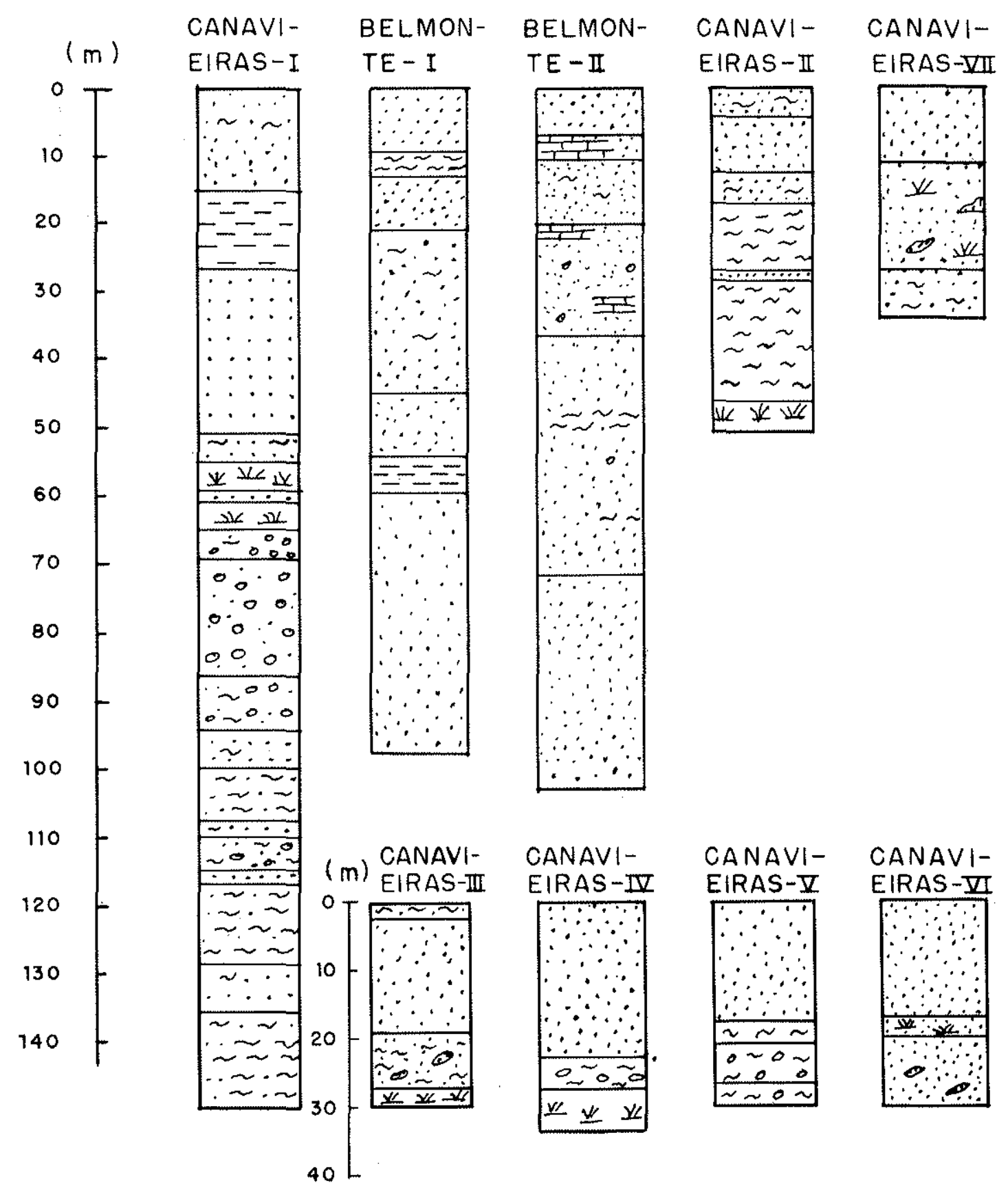

Figura 2.2 - Perfis litológicos dos poços tubulares do litoral sul da Bahia (Fonte: CERB, 1975)

Os poços de Santa Cruz de Cabrália, locados diretamente sobre os sedimentos da formação Barreiras, apresentam baixos valores de vazão, $4,46 \mathrm{~m}^{3} / \mathrm{h}$ e 7,99 $\mathrm{m}^{3} / \mathrm{h}$, devido, provavelmente, à falta de individualização das camadas areníticas puras, exceto numa espessura de 10 metros, no poço Pl. As vazões especificas variam de $0,21 \mathrm{~m}^{3} / \mathrm{h} / \mathrm{m}$ a $0,41 \mathrm{~m}^{3} / \mathrm{h} / \mathrm{m}$. Tais valores concordam com os valores médios obtidos por Brito Neves e Manoel Filho (1972), para a formação Barreiras das Bacias Sedimentares do Recôncavo e de Almada.

Os poços da zona III atravessam rochas calcárias intercaladas por sedimentos clásticos areniticos, argilosos ou arenosos. Sabemos que o comportamento hidro- geológico do calcário è bastante anisotrópico, sendo condicionado pela presença de juntas, fendas, cavernas, etc. Entretanto, como o calcário atravessado pelos poços encontra-se intercalado com material clástico, a porosidade responsável pelo armazenamento da água subterrânea não tem natureza dominantemente cárstica. Isso explica a uniformidade dos valores de vazão, limitados dentro do intervalo $22,3 \mathrm{~m}^{3} / \mathrm{h}-56,6 \mathrm{~m}^{3} / \mathrm{h}$, exceto no poço da Vila de Teixeira de Freitas, que atravessa 45 metros de areia argilosa e muito argilosa, antes de atingir o embasamento cristalino. As vazões específicas dos poços dessa zona variam entre $0,41 \mathrm{~m}^{3} / \mathrm{h} / \mathrm{m}$ e 3,6 $\mathrm{m}^{3} / \mathrm{h} / \mathrm{m}$, em conseqüência dos elevados valores dos re- 


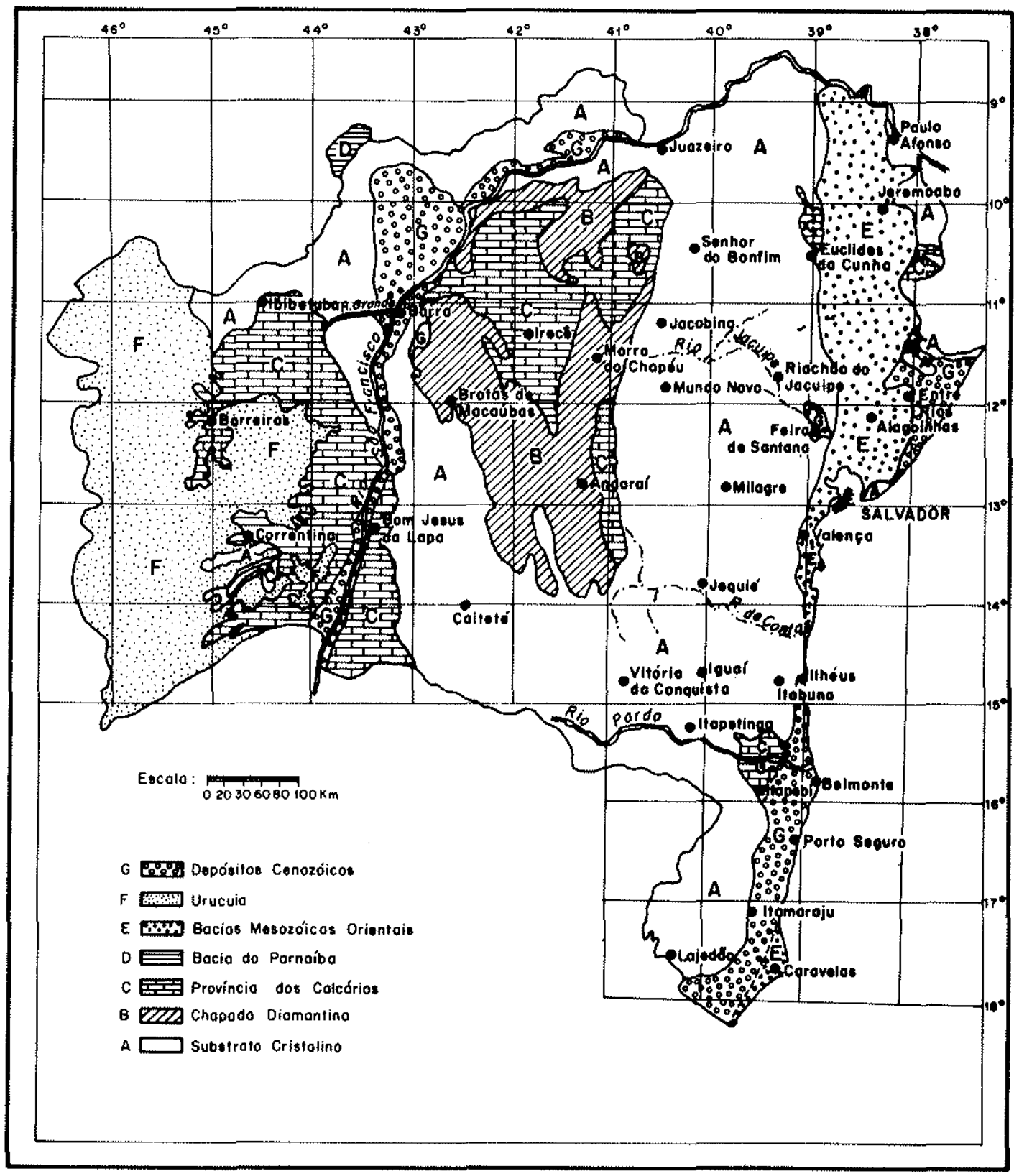

Figura 3 - Mapa das províncias hidrogeológicas do Estado da Bahia (Fonte: Brito Neves e J. M. Filho, 1972)

baixamentos. A transmissividade dos aquíferos confinados da zona III variam de $10^{-1} \mathrm{~m}^{3} / \mathrm{h} / \mathrm{m}$ (para os poços jorrantes de Alcobaça) a $10^{-3} \mathrm{~m}^{3} / \mathrm{h} / \mathrm{m}$ (para o poço de Teixeira de Freitas).

Foram feitas análises químicas das águas encontradas nos poços, com vistas à determinação de $\mathrm{Ph}$, cor, turbidez, sólidos totais, nitratos, nitritos e dureza. Os resultados não desaprovam a sua utilização para o consumo ou para outros fins.

Dado o alto índice pluviométrico anual da faixa costeira, em geral $500 \mathrm{~mm}$ superior à evapotranspiração, podemos inferir que o principal alimentador do seu sistema de aquíferos é a precipitação pluviométrica. Por outro lado, como todos os cursos d'água que desembocam no Oceano Atlântico, pela faixa litorânea em estudo, têm origem em pontos distantes da costa, todos eles também contribuem para a renovação dos aquiíferos, principalmente na época de suas enchentes.

Não obstante o pequeno número de poços perfurados no litoral sul do Estado da Bahia, que, de maneira nenhuma pode conduzir a resultados estatísticos confiáveis, acreditamos que os aquíferos da área tenham potencialidade hídrica para fornecer uma quantidade de água bem maior do que a que vem sendo consumida atualmente. Baseamo-nos, para essa afirmativa, não só nas características granulométricas e de cimentação das rochas porosas, mas também na constante realimentação dos aquíferos e, em terceiro lugar, nos resultados quantitativos de vazão, transmissividade e vazão específica. Do ponto de vista econômico, é muito conveniente a exploração de suas reservas de água subterrânea, por meio de poços tubulares, tendo em vista os baixos valo- 
Tabela 1 - Elementos hidrogeológicos de poços do sul da Bahia

\begin{tabular}{|c|c|c|c|c|c|c|c|c|c|}
\hline Municipio & № do poço & $\begin{array}{l}\text { Profundidade } \\
\text { (m) }\end{array}$ & $\begin{array}{l}\text { Nivel estático } \\
\text { (m) }\end{array}$ & $\begin{array}{l}\text { Nivel dinâmico } \\
(\mathrm{m})\end{array}$ & $\begin{array}{l}\text { Rebaixamento } \\
\text { (m) }\end{array}$ & $\begin{array}{l}\text { Vazăo } \\
\left(m^{3} / h\right)\end{array}$ & $\begin{array}{c}\text { Vazão especif. } \\
\left(\mathrm{m}^{3} / \mathrm{h} / \mathrm{m}\right)\end{array}$ & $\begin{array}{l}\text { Transmissivid. } \\
\left(\mathrm{m}^{2} / \mathrm{min} .\right)\end{array}$ & Tipo aquiffero \\
\hline Canavieiras & PII & 51,0 & 2,50 & 3,62 & 1,12 & 33,0 & 29,46 & 2,5 & livre \\
\hline Canavieiras & PIII & 22,6 & 3,20 & 9,00 & 12,20 & 6,0 & 0,49 & $4,4 \times 10^{-2}$ & livre \\
\hline Canavieiras & PIV & 30,0 & 1,45 & 3,78 & 2,33 & 41,6 & 17,85 & 2,1 & livre \\
\hline Canavieiras & PV & 22,6 & 1,30 & 3,10 & 1,80 & 14,4 & 8,0 & - & livre \\
\hline Canavieiras & PVI & 22,5 & 3,20 & 11,00 & 7,80 & 2,2 & 0,28 & - & livre \\
\hline Canavieiras & PVII & 32,0 & 0,80 & 1,41 & 0,61 & 36,0 & 59,0 & 1,0 & livre \\
\hline Belmonte & PI & 97,0 & 0,48 & 30,75 & 30,27 & 39,6 & 1,31 & $1,6 \times 10^{-2}$ & confinado \\
\hline Belmonte & PII & 100,0 & $1, \infty$ & 14,82 & 13,82 & 52,8 & 3,82 & $0,6 \times 10^{-1}$ & confinado \\
\hline $\begin{array}{l}\text { Sta. Cruz } \\
\text { Cabrália }\end{array}$ & PI & 53,4 & 1,20 & 22,40 & 21,30 & 4,46 & 0,21 & $1,8 \times 10^{-3}$ & livre \\
\hline $\begin{array}{l}\text { Sta. Cruz } \\
\text { Cabrália }\end{array}$ & PII & 53,0 & 2,50 & 22,00 & 19,50 & 7,99 & 0,41 & $0,93 \times 10^{-2}$ & livre \\
\hline Prado & PI & 100,6 & 0,60 & 18,50 & 18,10 & 22,3 & 1,23 & $2,9 \times 10^{-3}$ & confinado \\
\hline Prado & PII & 105,0 & 2,30 & 10,00 & 7,70 & 23,4 & 3,04 & $2,0 \times 10^{-2}$ & confinado \\
\hline Nova Viçosa & PI & 109,2 & 3,00 & 14,25 & 11,25 & 26,4 & 2,35 & $5,0 \times 10^{-2}$ & confinado \\
\hline Caravelas & PI & 105,5 & 3,60 & 13,90 & 10,30 & 24,7 & 2,40 & - & confinado \\
\hline Alcobaça & PI & 129,0 & jorrante & 15,71 & 15,71 & 56,6 & 3,60 & $1,0 \times 10^{-1}$ & confinado \\
\hline Alcobaça & PII & 127,0 & jorrante & 20,67 & 20,67 & 46,6 & 2,25 & $0,89 \times 10^{-1}$ & confinado \\
\hline Alcobaça & $\begin{array}{c}\text { Teixeira de } \\
\text { Freitas }\end{array}$ & 70,0 & 3,60 & 32,00 & 28,4 & 2,8 & 0,1 & $10^{-3}$ & \\
\hline
\end{tabular}

* $\mathrm{P} /$ rebaixamento $\mathrm{T}=1,67 \times 10^{-2}$.

res de profundidade do nível dinâmico, raramente superiores a $\mathbf{3 0}$ metros.

Para uma locação mais conveniente dos futuros poços de exploração, aconselhamos uma pesquisa detalhada dos aquíferos, nas proximidades de cada centro urbano, no sentido de delimitar a extensão lateral e vertical dos diversos níveis porosos. Infelizmente, o custo da perfuração é muito alto, e a prospeç̧ão de água subterrânea por esse meio é sempre muito onerosa. Devido a essa limitação de ordem econômica, achamos conveniente a aplicação de métodos geofísicos elétricos, os quais, além de serem muito menos dispendiosos, são bastante adequados para aquela finalidade, dada a sua capacidade em distinguir camadas argilosas de camadas arenosas ou calcários.

Como ilustração, vamos apresentar os resultados de uma campanha geofísica realizada na zona 1 , nas imediações das cidades de Belmonte e de Canavieiras.

ESTUDO GEOFISICO DOS AQÜÍFEROS DA ZONA I Os aquíferos da zona I são constituídos de camadas arenosas intercaladas por rochas argilosas. Dado o alto contraste de condutividade elétrica apresentado por esses dois meios sedimentares, o método geofísico de eletrorresistividade destaca-se como o mais conveniente na pesquișa da extensão lateral e vertical dos aquíferos arenosos.
O trabalho de campo, realizado com um terramimetro ABEM-5310, da ATLAS Copco, constou de 74 sondagens elétricas Wenner (Fig. 4) distribuídas sobre os aluviōes quaternários de Belmonte e de Canavieiras. A extensão das sondagens, limitada pela abundância de mangues na área, em geral foi da ordem de 384 metros.

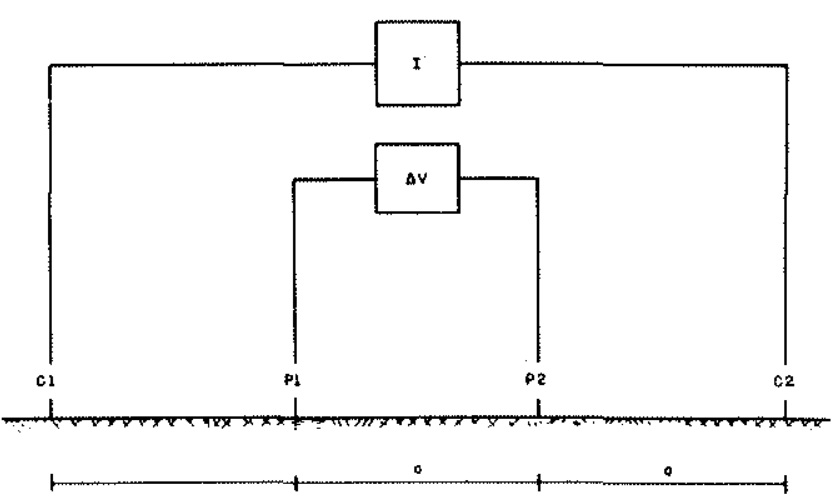

Figura 4 - Disposição dos eletrodos na sondagem elétrica Wenner 
As curvas de resistividade elétrica aparente obtidas no campo são geralmente do tipo QH (Keller, 1970), representativas de estruturas estratificadas de quatro camadas (Fig. 5). Depois de suavizadas visualmente, adotando-se o critério desenvolvido por Habberjam e Watkins (1967), as curvas foram submetidas a uma interpretação preliminar pela conhecida técnica do "ponto auxiliar"' (Meidav, 1960). Os modelos geoelétricos resultantes dessa primeira interpretação foram tomados como modelos iniciais para a interpretação por superposição total baseada numa técnica semi-automática proposta por Ghosh'(1971)

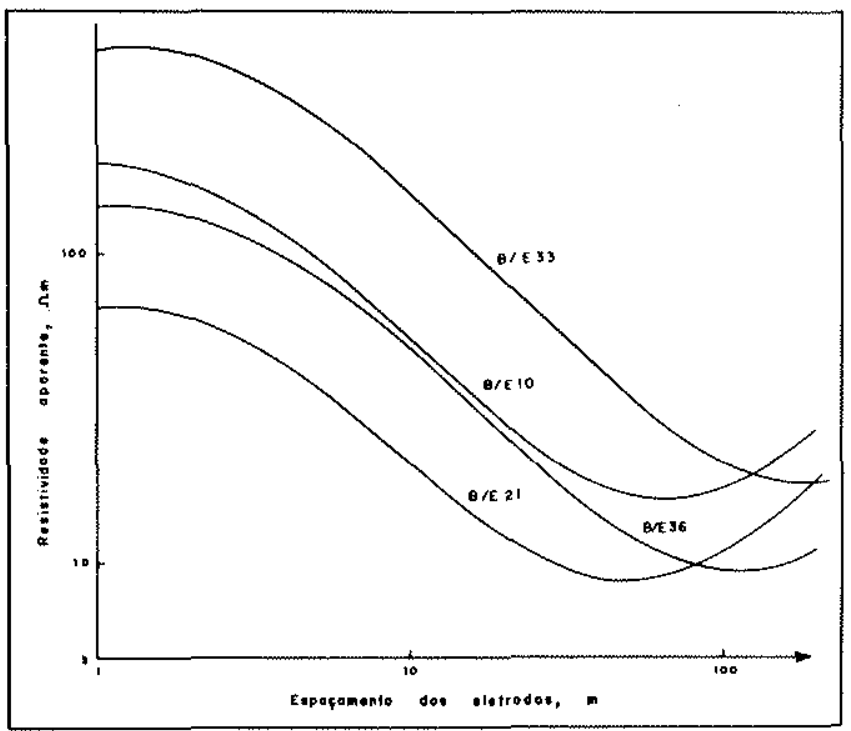

Figura 5 - Curvas típicas de resistividade aparente, obtidas em Belmonte e em Canavieiras

As resistividades obtidas em Canavieiras revelaram um subsolo constituído basicamente de quatro camadas geoelétricas. A correlação geológica dessas camadas foi conduzida comparando-se as secções geoelétricas das sondagens Wenner vizinhas aos poços perfurados pela CERB, com os seus respectivos perfis estratigráficos (Fig. 6).

A camada superficial tem espessura variando entre $1 \mathrm{~m}$ e $3 \mathrm{~m}$ e resistividade entre $150 \Omega \mathrm{m}$ e $5.000 \Omega \mathrm{m}$, a depender da composição do solo.

A segunda camada apresenta resistividade no intervalo $45 \Omega \mathrm{m}-220 \Omega \mathrm{m}$, e corresponde a material permeável constituído de areias e cascalhos saturados. As variaçðes na resistividade estão relacionadas a mudanças nas propriedades hidrogeológicas do aquífero e a variação na resistividade da água intersticial, cujos valores, determinados em laboratório, oscilam entre $5 \Omega \mathrm{m}$ e $150 \Omega \mathrm{m}$. É essa camada arenosa que vem fornecendo a água consumida pela população de Canavieiras. Sua espessura é superior a $15 \mathrm{~m}$, em quase toda a área (Fig. 7).

A areia saturada encontra-se sobre um meio de muito baixa resistividade, correspondente ao material argiloso exibido nos perfis litológicos dos poços. Essa camada argilosa, misturada algumas vezes com rochas de natureza orgânica, em geral encontra-se intercalada por finas camadas de areia, arenito ou conglomerado, não diferenciadas individualmente pelas sondagens elétricas. A sua espessura é bem maior que a da areia.

A última camada, encontrada a uma profundidade superior a $50 \mathrm{~m}$, é altamente resistiva. Lamentavelmente, os poços da CERB não ultrapassaram o estrato argiloso, o que dificulta a correlação geológica dessa camada. Entretanto, como o embasamento cristalino é bastante profundo na área (relatórios internos dos poços SAI -BA e CNP1-BA, PETROBRÁS), é bem provável que a última camada seja também constituída de rocha sedimentar, consolidada ou não, pertencentè à Formação Barreiras. Infelizmente, o nosso terramímetro não permitiu que se definisse a espessura dessa rocha nem que se determinasse valores mais precisos para a sua condutividade elétrica.

Resumindo, podemos afirmar que os estudos geofísicos conduzidos em Canavieiras concluem pela existência de um aqiífero arenoso bem próximo da superfície, com espessura acima de $15 \mathrm{~m}$, sobrejacente a uma espessa camada de argila.

A porosidade, $\Phi$, desse aquiifero pode ser estimada através da fórmula de Archie (1950):

$$
P_{\mathrm{x}}=a P_{\mathrm{h}} \phi^{-m}
$$

onde $a$ e $m$ são parâmetros característicos da rocha, $P_{\mathrm{h}}$ é a resistividade da água que preenche os poços da rocha e $P_{\mathrm{x}}$ é a resistividade da rocha.

Para rochas inconsolidadas, Wyllie e Gregory (1953) encontraram os valores $a=1$ e $m=3$. Os valores médios da resistividade da água intersticial e do aquífero, determinados a partir de amostras de água dos poços caseiros, e dos résultados numéricos da interpretação das sondagens elétricas, são iguais a $62 \Omega \mathrm{m}$ e $124 \Omega \mathrm{m}$, respectivamente. Aplicando esses valores numéricos à equação (1) obtém-se uma porosidade de $58 \%$, a qual caracteriza bons aquíferos, conforme estudos estatísticos reportados por Davis (1965).

$O$ teor de argila, $x$, de um aquífero inconsolidado pode ser estimado pela fórmula de Astier (1971), dada por

$$
\frac{1}{P}=\frac{x}{P_{\mathrm{C}}}+\frac{1-x}{P_{\mathrm{S}}}
$$

onde $P_{\mathrm{S}}$ é a resistividade do material sólido constituinte do aquífero, admitida igual ao máximo valor encontrado para a porosidade que, no nosso caso, é $8.300 \Omega \mathrm{m}$, e $P_{C}$ é a resistividade da argila, admitida igual ao menor valor de resistividade encontrada: $0,82 \Omega \mathrm{m}$. Substituindo esses valores na equação (2), obtém-se um teor de argila baixíssimo, da ordem de $0,7 \%$. Ressalvados os erros provenientes das suposiçðes feitas, podemos considerar bastante puro o aquífero estudado.

$O$ valor médio do coeficiente de permeabilidade pode também ser estimado, dividindo-se a transmissividade média do aquífero, igual a $1,41 \mathrm{~m}^{2} / \mathrm{min}$, pela sua espessura. Esta normalmente atinge até 28 metros na área, resultando numa permeabilidade de $5 \times 10^{2} \mathrm{~m} / \mathrm{min}$. De acordo com Todd (1959), esse valor caracteriza bons aquíferos.

Os resultados quantitativos apresentados permitem concluir que, em Canavieiras, o aquífero mais próximo 


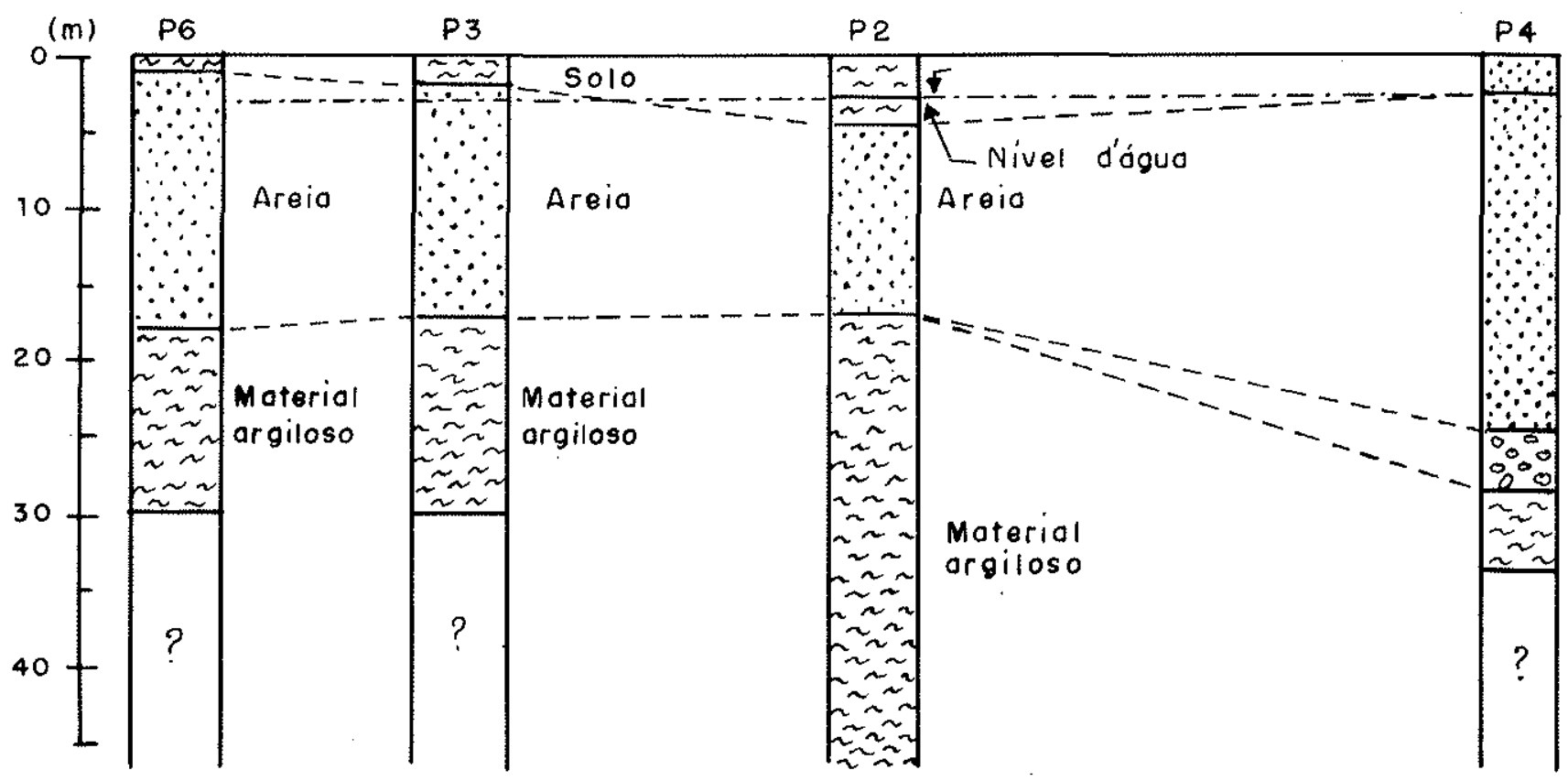

Escalo horizontal:
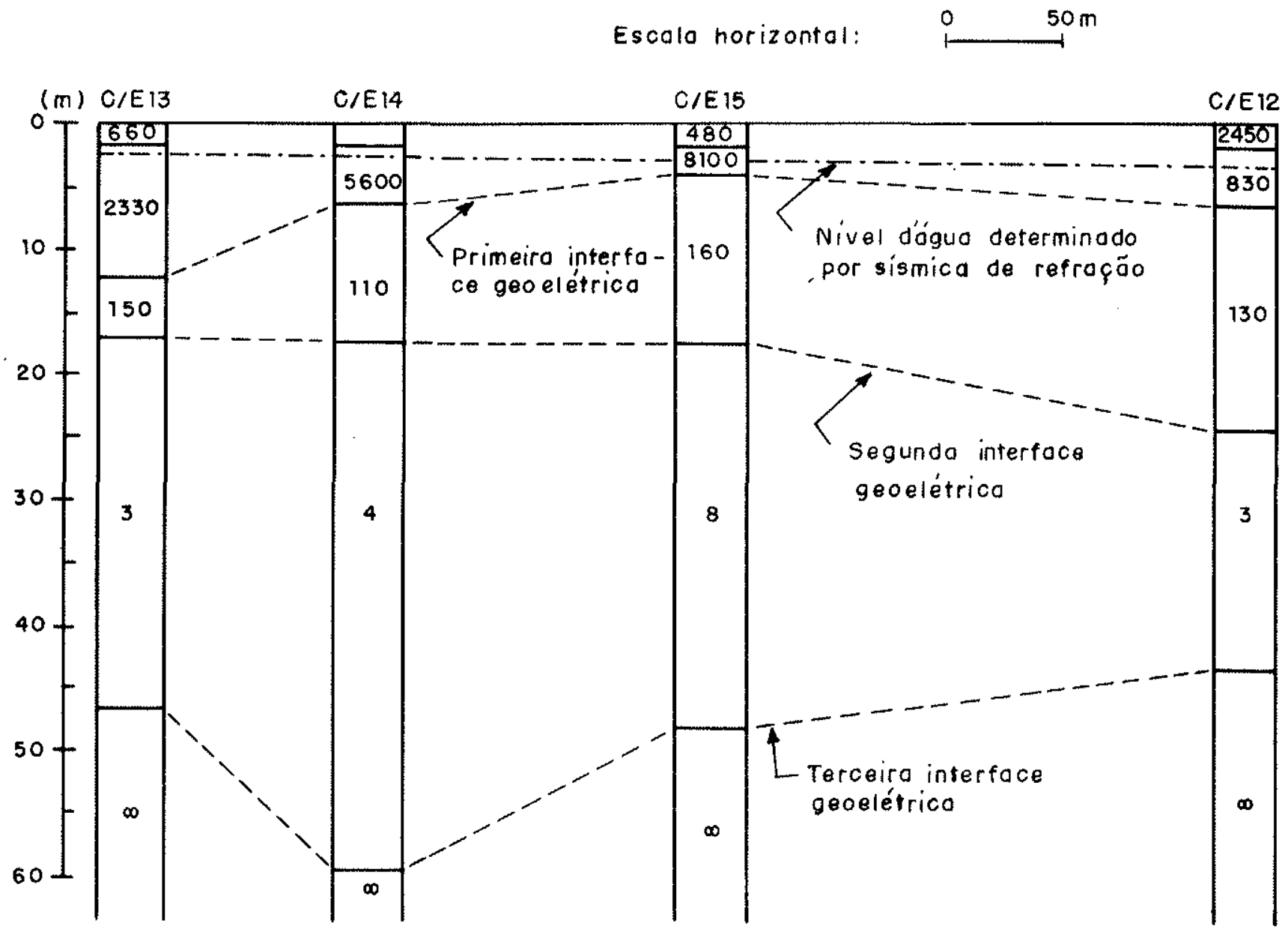

Figura 6 - Seçăo geoelétrica vertical (acima) em confronto com a correlação estratigráfica dos poços de Canavieiras. Os números expressam resistividades $\mathrm{em} \mathrm{ohm} /$ metro 


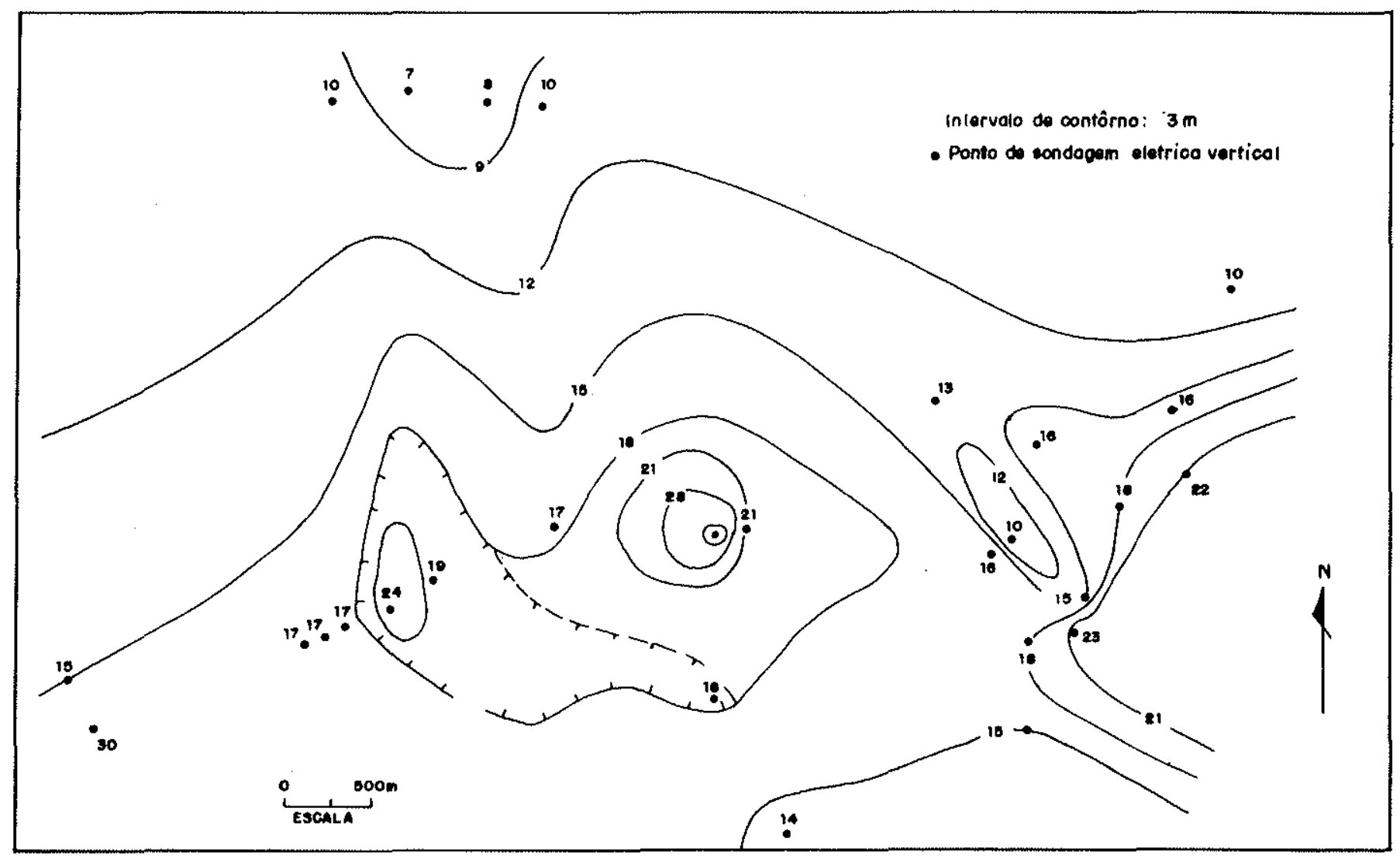

Figura 7 - Mapa de isoespessura do aquiifero próximo da superfície, detetado em Canavieiras. A área mais favorável para exploração encontra-se grifada

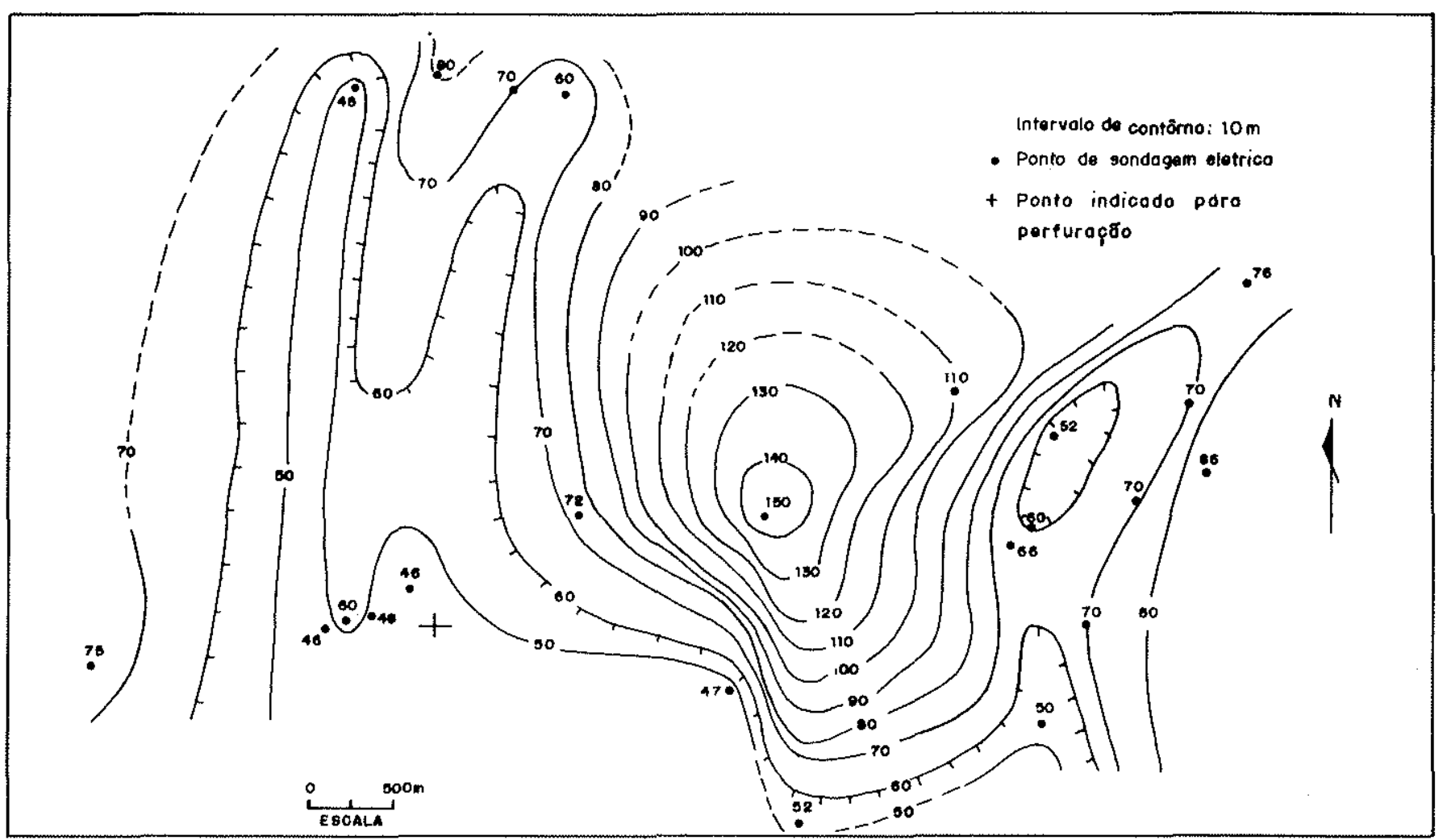

Figura 8 - Mapa de isoprofundidade da base da camada argilosa detetada em Canavieiras 
da superfície apresenta muito boas propriedades hidrogeológicas. $\mathrm{O}$ exame do mapa de espessura do aquífero (Fig. 7) permite definir as zonas potencialmente mais favoráveis para exploração da água subterrânea, as quais correspondem às maiores espessuras do aquífero. Por outro lado, há grande probabilidade de existência de outro aquífero, também economicamente explorável, logo abaixo da camada de material argiloso. Para confirmação, sugerimos que seja feito um furo na posição indicada no mapa de profundidade da base do material argiloso (Fig. 8).

A interpretação das sondagens elétricas executadas em Belmonte revelaram, também, a presença de quatro camadas geoelétricas. Entretanto, existe uma superposição entre os valores de resistividade da primeira e da segunda camadas. Isso parece indicar que em Belmonte o nivel d'água está bastante próximo da superfície, de tal modo que nem sempre foi possivel distinguir a areia saturada da areia seca por eletrorresistividade. Observações diretas do nível d'água em dezenras de poços reforçam essa conclusão.

A escassez de dados de informações diretas dificultaram a interpretação geológica das sondagens elétricas de Belmonte. Os dois únicos poços profundos existentes na área estavam circundados por enormes rios provisórios que prejudicaram a qualidade das curvas de resistividade aparente das sondagens vizinhas a eles. Esse fato explica porque a correlação entre o corte geoelétrico e a secção estratigráfica não se verificou plenamente (Fig. 9).

Não obstante a carência de dados de perfuração, é possivel tecer algumas considerações interessantes sobre os diversos estratos geoelétricos encontrados.

A primeira camada geoelétrica, com espessura variando entre $1 \mathrm{~m} \mathrm{e} 7,6 \mathrm{~m}$, representa a zona de aeração do solo e tem resistividade entre $13 \Omega$ m e 10.600 凡m. Esse amplo intervalo de variação explica a diversidade do solo da área, o qual se apresenta como areia pura, na praia, como argila ou areia misturada com matéria orgânica, numa faixa posterior, voltando a ser areia seca bastante resistiva mais para o interior.

A segunda camada, indicada por somente $2 / 3$ das sondagens, apresenta resistividades dentro do intervalo 32,5 $\Omega \mathrm{m}-280 \Omega \mathrm{m}$, e corresponde, nos perfis litológicos dos poços da CERB, a uma camada arenosa permeável. A espessura dessa camada arenosa raramente ultrapassa 10 metros (Fig. 10).

O terceiro grupo de valores de resistividade, variando entre $0,9 \Omega \mathrm{m}$ e $25 \Omega \mathrm{m}$, caracteriza um meio bastante condutivo, cuja base alcança profundidades desde 20 metros até 60 metros. A sua constituição pode ser areia argilosa, folhelho, argila arenosa ou até mesmo areia saturada com água salgada. Em qualquer dessas hipóteses, essa camada não pode ser aproveitada como fonte de água potável.

A última camada em geral é muito resistiva. Contudo não temos condições de estimar com uma boa margem de segurança a sua resistividade, dado o baixo nú mero de pontos que define a última parte das curvas de resistividade aparente obtidas no campo. Há grande possibilidade, contudo, dessa camada constituir um bom aquífero confinado, com profundidade entre 30 e 40 metros, pois os perfis estratigráficos dos dois poços de Belmonte revelam uma considerável espessura de areia inconsolidada, sob o material argiloso (Fig. 2). Os testes de bombeamento desses poços forneceram elevados valores de vazão (Tab. 1).

CONCLUSÕES A análise dos dados de perfuração disponíveis, bem como os resultados da interpretação dos testes de bombeamento dos poços, permitiram ava-

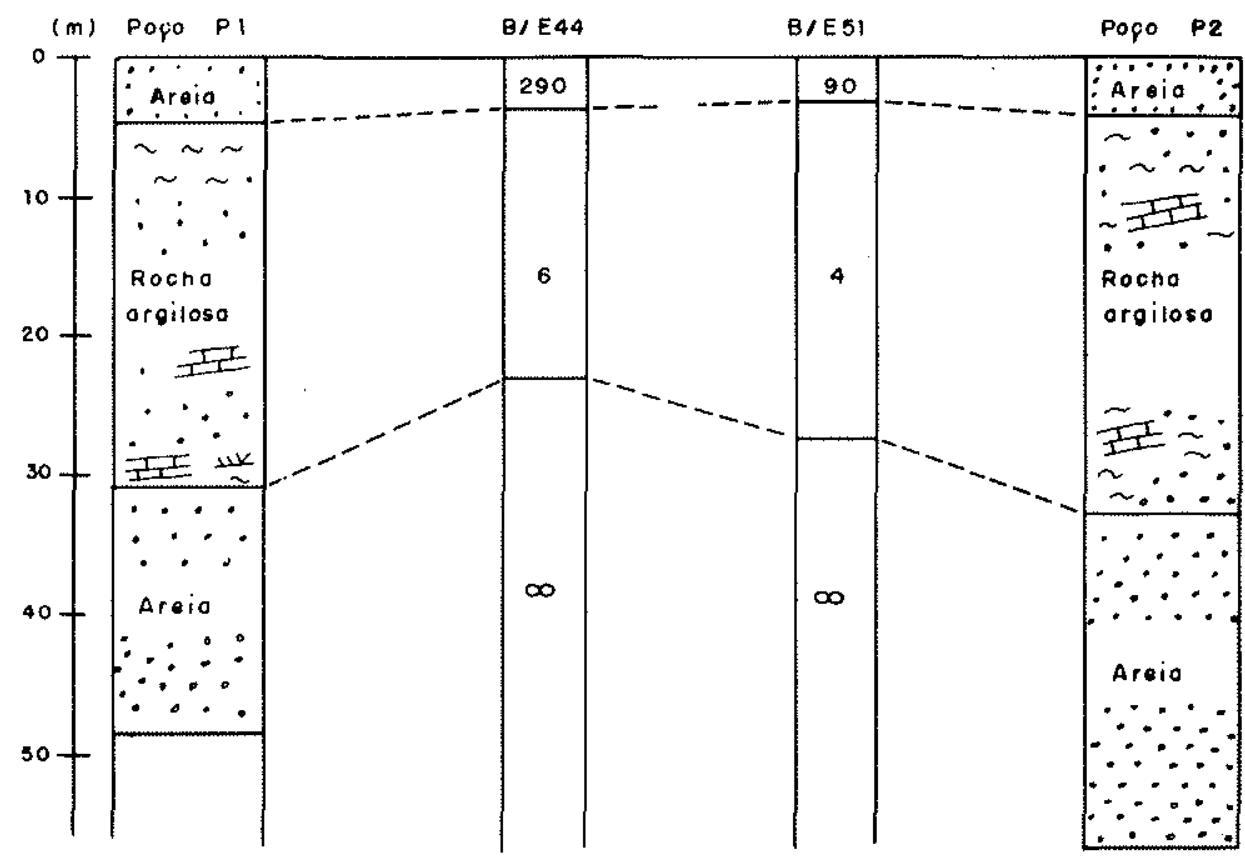

Figura 9 - Seção vertical obtida com dados de poços e de sondagens elétricas em Belmonte. Os números indicam resistividades em ohm/metro 


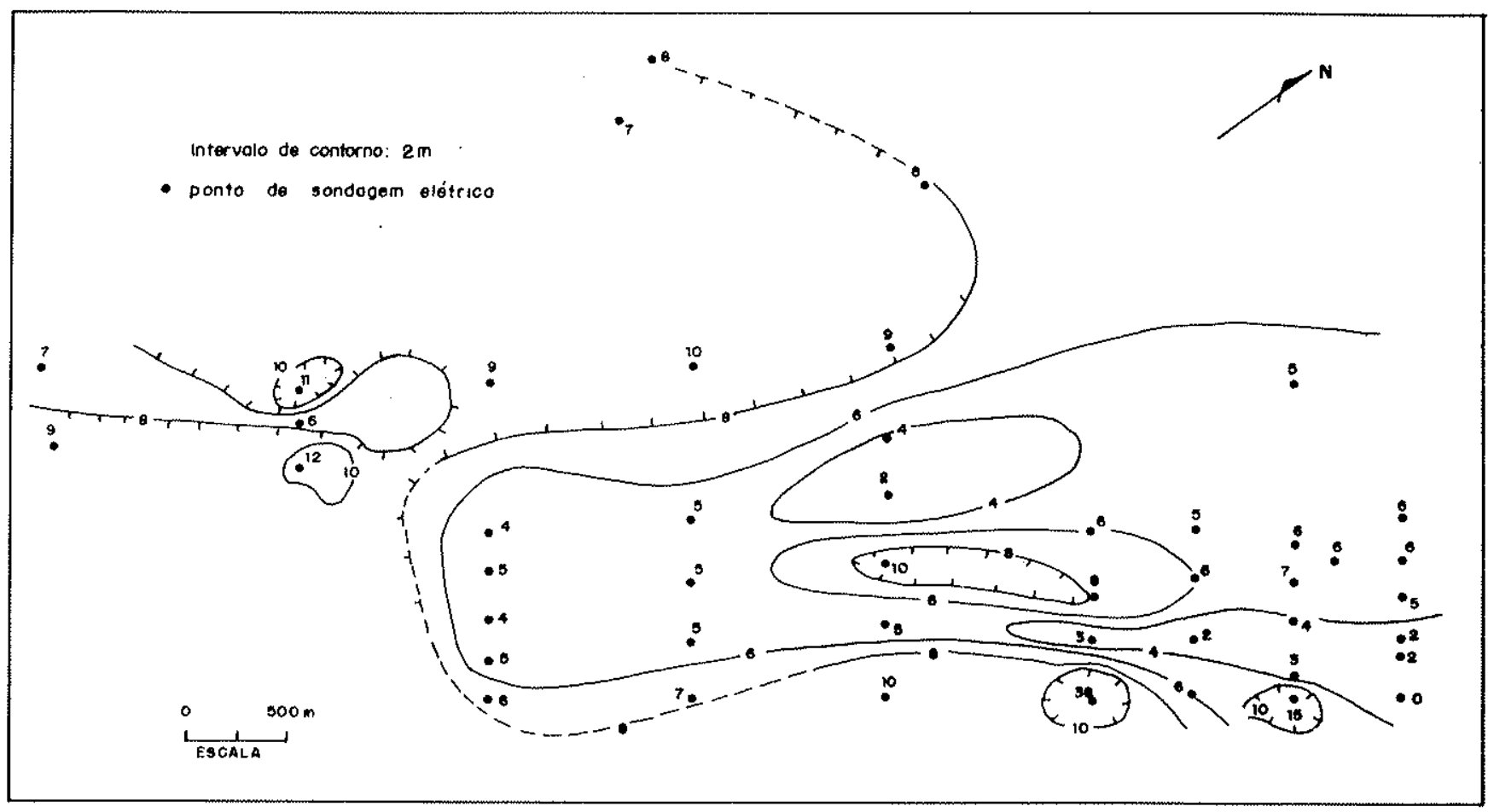

Figura 10 - Mapa de isoespessura do aquíifero próximo da superfície, detetado em Belmonte

liar algumas características hidrogeológicas dos aquíferos do litoral sul do Estado da Bahia, mostradas na Tab. 1. Entretanto, para um melhor planejamento da exploração da água subterrânea, em cada cidade, torna-se importante um estudo detalhado das propriedades hidrodinâmicas e das dimensões dos aquíferos. Os dois exemplos apresentados mostram que esse estudo pode ser conduzido, de maneira econômica, através do método geofísico de eletrorresistividade.

Em Canavieiras, foi possível delimitar um aquífero livre, com espessura em torno de 15 metros, estendendo-se por toda a área pesquisada, e com boas condiçóes de fluxo e de armazenamento. Foi também vislumbrada a presença de um aquífero confinado, com profundidade em torno de 54 metros, no topo.

Em Belmonte, a camada permeável próxima da superfície não oferece condições para ser sistematicamente explorada, devido à sua descontinuidade lateral e reduzida espessura, normalmente inferior a 8 metros. Os resultados da interpretação geofísica confirmaram a presença do aquífero confinado revelado pelos perfis litológicos dos poços perfurados pela CERB. Entretanto, não foi possivel determinar a sua espessura, devido à limitada potência do resistivímetro empregado nessa pesquisa. Recomendamos exploração mais profunda, para elucidação desse problema.

\section{BIBLIOGRAFIA}

ARCHIE, G.E, - 1950 - Introduction to petrophysics of reservoir rocks, Builetin of the American Assoc. of Petroleum Geologists, 34: 943.961.

ASMUS, H.E. et al. - 1971 - Integração Geológica Regional da Bacia do Espí rito Santo, Salvador, RPBA, PETROBRÁS, relatório interno.

ASTIER, J.L. - 1971 - Geophysique appliqueé a l'hidrologie, Masson e Cie, Paris

BRITO NEVES, B.B. e FlLHO, J.M. - 1972 - Geologia e Províncias Hidrogeológicas da Bahia, XXVI Congresso Brasileiro de Geologia, vol. 3.

CARVALHO, K.W.B. e GARRIDO, J.L.P. - 1966 - Reconbecimento geológico da Bacia Sedimentar do Sul da Bahia e Espirito Santo, PETROBRAS, relatório interno.

CEPLAC - 1975 -... Reconthecimento Climátológico, Diagnóstico Sócio-Econô. mico da Região Cacaucira, vol. 4.

CERB - 1975 - Cadastro de Pocos Tubulares do Estado da Bahia.

DAVIS, S.N. - 1965 - Porosity, Permeability of natural materials, in flow through porous medja; edited by Roger de Wiest, Academic Press, 54-89, New York.

GHOSH, D.P. - 1971 - The application of tinear filter theory of the direct interpretation of geoclectrical resistivity sounding measurements, Geophysical Prospecting, 19: 192-217.

GUERRA, A.M. - 1973 - Contribuição ao conhecimento hidrogeológico do Extremo Sul da Balija, XXVII Congresso Brasi\}eiro de Geologia, vol, 2
HABBERJAM, G.M e WATKINS, G.E. - 1967 - The reduction of lateral effects in resistivity probing, Geophysical Prospecting, 15: 22I-235.

KELLER, G.V. e FRISHKNECHT, F.C. - 1970 - Electrical methods in Geophysical Prospecting, Pergamon Press, Oxford, 1-55 e 90-196.

LEITE, J,L. - 1975 - Estudo Geolisico dos Aquiiferos Costeiros nas áreas de Canavieiras e Belmonte, Bahia, Universidade Federal da Babia, tese de mestrado.

MEIDAV, T. - 1960 - An electrical resistivity survey for groundwater, Geophysics, 25: 1077-1093.

MINISTËRIO DA AGRICULTURA - 1972 -.... Balanço Hidrico do Brasil, Depart. Nacional de Meteorologia, Bahia.

MINISTERIO DAS MINAS E ENERGIA - 1974 - Convênio DNPM/CPRM, Projeto Sul da Bahja.

M. FILHO, N.R. - 1972 - Geologia dos Quadriculos de Porto Seguro Nordeste e Mogiguiçaba, CEPLAC, Boletim Técnico 17.

PEDREIRA, J,A. - 1971 - Geologia da Faixa Costeira de Canavieiras e Belmonte, CEPLAC.

TODD, D.K. - 1959 - Hidrologia de águas subterrâneas, Edgar Blücher Lıda., Sảo Paulo.

WYL.LIE, M.R.J, e Gregory, A.R. - 1953 - Formation Factor of unconsolidated porouss media, Trans. A.I.M.E., 198: 103-110. 